\title{
Africa seeks laws on GM food exports ...
}

[LONDON] African countries are to be asked to introduce legislation that would make it illegal for a country to export genetically modified (GM) food without first seeking permission from the importing country.

The move comes in response to the collapse of talks on an international biosafety protocol earlier this year (see Nature 398, 6; 1999). African countries had wanted to insert a clause to this effect in the protocol, but this suggestion was strongly opposed by a consortium of grain-exporting countries led by the United States, and known as the Miamigroup.

These countries argued that a product that has passed safety tests in its country of origin should not need permission - or additional risk assessments - from an importing country.

The draft Africa legislation, which has been drawn up by a small group of countries led by Ethiopia, says that any person or organization intending to export GM food or use GM organisms in a laboratory or for field trials must carry out an evaluation of the risks to the environment, biological diversity and human health. Such an evaluation will also include socio-economic risks, such as the impact on jobs.

The draft says that permission will only be granted if the GM product does not pose risks of "adverse socio-economic impacts", and if it "accords with the ethical values and concerns of communities and does not undermine traditional knowledge and technologies". Under the draft, an exporter will also be liable to pay compensation for any harm caused by the GM material.

"No approval shall be given unless there is firm and sufficient evidence that the GM organism or the product of a GM organism poses no risks to the environment, biological diversity or health. Where there is reason to suspect threats of serious damage, lack of scientific evidence should not be used as a basis for not taking preventive measures," says the draft legislation.

The final draft is expected to be completed next year when individual governments will be lobbied to adopt the proposals. "A few African countries have now decided to take the initiative and introduce national biosafety legislation in as many countries as possible," says a source close to the Ethiopian government. "We don't necessarily need to wait for an international protocol."

Introducing Africa-wide legislation, however, is fraught with difficulties. Last year, for example, heads of state of the Organization of African Unity (OAU) agreed to adopt a continent-wide law banning patents on natural products until the World Trade Organization modifies its rules on patenting in line with the United Nations Biodiversity
Convention. But so far there has been no follow-up in any country.

One reason is that the OAU has little practical influence in the continent. Another is that trade and foreign ministries in Africa will not support any proposed law likely to antagonize France - which maintains considerable influence in the continent or the United States. Neither ministry is likely to agree to a set of measures that are a direct challenge to the international trading system.

Countries belonging to French-speaking Africa have already agreed in principle to accede to the UPOV convention (see Nature 398, 99; 1999), which grants plant breeders intellectual-property rights over the commercialization of products such as seed. English-speaking countries in Africa are expected to follow suit.

At a meeting of OAU heads of state last month, Salim Ahmad Salim, the secretarygeneral of the OAU and a former prime minister of Tanzania, appealed for countries to adopt legislation making it compulsory for companies that have developed medicines from natural products to share the benefits with local communities.

EhsanMasood
[PÔRTO ALEGRE, BRAZL] Scientists attending a meeting of the Brazilian Society for the Progress of Science (SBPC) in Pôrto Alegre, the capital of the state Rio Grande do Sul, have condemned the state government's proposal to ban all genetically modified (GM) crops.

Francisco Mauro Salzano, a prominent geneticist at the Federal University of Rio Grande do Sul, described the state government's attitude as "medieval", and compared it to Stalin's support of the agronomist Trofim Lysenko, whose ideas about genetics put back Soviet agriculture for many decades.

But at the opening ceremony of the SBPC meeting last month, the state's left-wing governor, Olivio Dutra, said that in his state "we do not want Stalin's dictatorship, the same way that we don't want the dictatorship of Monsanto". The move to ban GM crops from the state has yet to be passed by the state legislature.

Monsanto has recently applied to the federal government to import and commercialize soy seeds that have been genetically modified for resistance to the company's herbicides. Brazil's biosafety legislation regulates both the release of GM organisms into the environment and the sale of GM foods through the

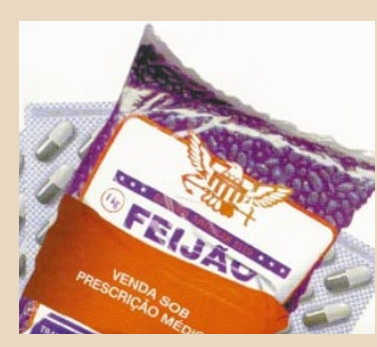

Doctored label: black beans are used in a GM health scare.

National Technical

Commission for Biosafety (CTNBio).

But even though CTNBio has given the green light to Monsanto, environmental and consumer groups are mounting a legal challenge to the import of seeds. Critics of these groups suspect a political agenda, however. A leaflet distributed by the state government shows a bag of black beans - a staple part of the Brazilian diet - with the label, in English, "original American seed" beneath an American eagle, and another, in Portuguese, that reads "for sale only with medical prescription".

The environmental group Greenpeace has sought to turn Rio Grande do Sul into a "transgenics free state". And a Rio Grande organization of landless peasants has vowed to burn any soy fields using GM seeds.

But Salzano's criticism of the state policy has the support of many Rio Grande researchers. "The debate is being carried in a doctrinaire, even fanatical way," says José Francisco Valls of the agriculture research institute Embrapa, which brings together the agricultural research units of the Brazilian Ministry of Agriculture.

"There is paranoia here regarding transgenics," says Maria Irene Baggio, also from Embrapa. She has a leaflet distributed by a local syndicate describing GM seeds as "the seeds of death". "Aggression towards scientists is constant in these debates," she says.

The only dissenting voice came from SBPC itself. Aware that the society has potential supporters of the ban among its members, it preferred to issue a more moderate statement urging caution and requesting a five-year moratorium in the use of GM seeds. During this period, more tests could be conducted in Brazil, according to SBPC's new president, Glaci Zancan, a biochemist from the Federal University of Paraná.

The state government of Rio Grande do Sul hopes to capitalize on European concern about GM foods by offering to export to Europe soy production labelled as GM-free. One leaflet, in English, says the government agrees that science should be "under public contro to benefit life, not under private control to [benefit] profit". Ricardo Bonalume Neto 